\title{
DEVELOPMENT OF A GEO-ANALYTICS PLATFORM FOR POST-DISASTER GROUND ASSESSMENT
}

\author{
Kubra Atasoy ${ }^{1}$, Sultan Kocaman ${ }^{1, *}$ \\ Hacettepe University, Dept. of Geomatics Engineering, 06800 Beytepe Ankara, Turkey - (kubra.atasoy, \\ sultankocaman)@ hacettepe.edu.tr
}

ICWG III/IVa

KEY WORDS: Geovisualization, Natural Hazards, Geo-analytics, GIS, Post-disaster Ground Assessment, Spatiotemporal Visualization, WebGIS

\begin{abstract}
:
Earthquake is a frequently encountered natural hazard and can cause losses of lives and assets. In order to understand the nature of seismic hazards and the risks sourced from them, careful investigations are needed by using diverse geoinformation types. Thanks to the availability of multi-platform and high-resolution geospatial datasets, vast amount of geodata can be collected and analyzed for obtaining timely information on land's surface before and after an earthquake event; and to assist the disaster management authorities and first responders for supporting the mitigation efforts. On January 24, 2020, an earthquake with Mw 6.8 occurred in Elazig Province, Turkey; caused 41 deaths and damaged the buildings and infrastructure. Although various geodatasets could be collected and processed by the geomatics experts, their utilization by other stakeholders, such as geoscientists, local authorities, and citizens remained limited due to the accessibility issues, and high complexity in their visualization, processing and interpretation. In this study, a web-based platform called EQ4D was designed and implemented to present the multi-sensor and multi-platform 4D data to the stakeholders, and to allow for basic geo-analytical processes such as change detection, 3D surface measurements, etc. Cesium JS and Potree libraries were employed for 3D visualization. PostGIS spatial database management system was used for storing and managing the data, and for performing spatial queries. Currently EQ4D is suitable for the use of geoscientists, and can be further customized for generic use at similar geohazards and developed for the use of inexperienced users, such as citizen scientists.
\end{abstract}

\section{INTRODUCTION}

Climate change and population growth combined with the rapid urbanization increased the vulnerability of cities to natural hazards. Within the 2030 Agenda of United Nations (UN) for sustainable development, a total of 17 Sustainable Development Goals (SDG) were defined. Among other goals and targets, such as ensuring equality, ending the poverty; the SDGs aim at increasing the resilience for disasters and reducing the vulnerability. The SDG targets $1.5,2.4,11.5,11 . b$, and 13.1 explicitly emphasize building resilience against climate-related hazards and natural disasters as well as other economic, social and environmental shocks and disasters (UN SDGs, 2020); while pointing out the need for a holistic disaster risk management at all levels in line with the Sendai Framework for Disaster Risk Reduction 2015-2030 (UN, 2015).

The potential contributions of geospatial technologies for the realization and monitoring of SDG indicators were discussed in several studies (e.g. Scott and Rajabifard, 2017; Pfeffer and Georgiadou, 2019, Zhilin et al., 2020; Kocaman and Ozdemir, 2020 ; etc.). The disaster management efforts also benefit from the advancements in geospatial data collection and visualization technologies. Advanced geovisualization techniques can support disaster management activities at various stages, such as pre-, during- and post-disaster. The novel visualization approaches such as virtual/mixed/augmented reality (VR/MR/AR), web globes (e.g. CesiumJS, Google Earth, etc.), and game engines (e.g., Unity) can aid to diverse stakeholders by improved communication of disaster-related data and supporting various processes, such as the training of first responders, citizens and volunteers taking part of the disaster resilience efforts, and decision-makers for better planning. In addition, scientists from various disciplines utilize geospatial technologies for efficient data collection and analysis even in areas with poor accessibility. Time is another important dimension since Earth surface may change rapidly that yields to loss of crucial information for geoscientific analyses. Thanks to the various data collection platforms, such as unmanned aerial vehicles (UAVs), airplanes, etc., and the higher availability of satellite Earth Observation (EO) sensors; the changes on the Earth's surface can be recorded frequently and thus allow multitemporal assessments.

On the other hand, the recent technological developments facilitated a new research field, geo-analytics, which aims at combining geospatial big data with advanced spatial analysis functionality on the web or mobile applications, and enabling user interaction via visualization and spatial querying (Boulos and Koh, 2021). Geo-analytics derived from visual analytics, which can be described as "the science of analytical reasoning facilitated by interactive visual interfaces" (Cook and Thomas, 2005); can increase the space-time awareness and the performances, and support the cognitive processes, such as pattern recognition and association by dealing with large-scale 4-dimensional (4D) data dynamically (Jern and Franzen, 2006; Ho and Jern, 2008; Keehner et al., 2011; Schumann and Tominski, 2011). The development of geo-analytics platforms for geoscience applications is immensely required for exploiting

\footnotetext{
* Corresponding author
} 
the potential of geospatial tools and technologies. A recent work can be found for landslide data analysis in Pirasteh (2018).

On January 24, 2020, an earthquake with Mw of 6.8 occurred in Sivrice town of Elazig Province, Turkey; and caused 41 deaths and more than 1600 injured. In addition, ca. 5000 buildings and various infrastructure were damaged (AFAD, 2020). It has also triggered several landslides (Gokceoglu et al., 2020; Karakas et al., 2021). Besides the emergency response teams, accurate assessment of the changes on the land surface has become important for the geoscientists for efficient analysis of the hazardous event (Gokceoglu et al., 2020). Advanced geomatics methods and tools can be used as an alternative or complement to field studies to detect earthquake-related ground changes. As witnessed during and after the event, post-earthquake ground assessments by the experts are very important to understand the hazard and manage it correctly.

The main aim of this study was to develop a 4D visualization and geo-analytics platform called EQ4D with the main purpose of serving to geoscientists and the citizen scientists, who are aiming to help the geoscience professionals for detailed spatial assessments and to support the decisions-makers. Thus, accessibility issues and overlooking the essential phenomena during the time-consuming field studies could be omitted. In addition, it can be possible to obtain more data and information about the natural hazards with the help of non-specialist volunteer citizens to collect information by interpreting images and contribute to the system. As a first step, the system designed here considered the algorithms and tools to identify post-disaster ground deformations and vulnerable elements under risk. Various solutions were implemented by determining the difficulties in web-based visualization of high-resolution 4D spatial data obtained from different sensors. The datasets from Sentinel-1 and Sentinel-2 satellites of European Space Agency (ESA, 2021), aerial photogrammetric datasets acquired at the pre- and post-event dates and the national topographic vector database obtained from the General Directorate of Mapping (GDM), Turkey, and the web feature service (WFS) from the United States Geological Survey (USGS) was utilized on EQ4D platform and presented for the study area.

\section{RELATED WORK}

3D visualization of geospatial data and dynamic scenes provide better perception to the users. Presentation of spatial datasets on virtual globes have become a frequently used approach in several application fields, such as post-disaster recovery (Fernando et al., 2006), rockfall hazard modelling (Lan et al., 2007), noise mapping (Stoter et al., 2008), landscape planning (e.g. Lovett et al., 2015), big climate data (Li and Wang, 2017), urban planning and campus modelling (Buyukdemircioglu and Kocaman, 2018, 2020), etc. Kilsedar and Brovelli, (2020) developed a web portal for a number of applications, such as 3D city models, ground deformation assessment, land use and land cover (LULC) assessment for dynamic presentation and interactive use via virtual globes, etc. Zhang et al. (2020) developed an interactive 3D visualization environment for hydrometeorological datasets with different formats, scales, dimensions, and temporal properties using NASA WorldWind (NASA WorldWind, 2014) virtual globe engine.

Although various web-based Geographical Information System (WebGIS) platforms have been developed for efficient disaster management by researchers and government authorities, the majority of them provide $2 \mathrm{D}$ geovisualization ability. Aye et al.
(2016) presented a 2D WebGIS framework with a multi-criteria evaluation tool for hydro-meteorological hazards. Lagmay et al. (2017) developed a 2D WebGIS environment for disseminating information on multiple natural hazards, such as floods, landslides, storms, etc. He et al. (2017) implemented a mobile and web-based post-disaster management system with crossplatform and offline-working capabilities. Heinzlef et al. (2020) proposed an accessible and at the same time comprehensible spatial decision support system for flood risk management and presented on a $2 \mathrm{D}$ WebGIS portal. They aimed at ensuring the accessibility for residents and communicating the risks via geovisualization. Vučić et al. (2020) demonstrated the efficiency of GIS and web technologies for post-disaster assessment after wildfires. Sylka et al. (2018) mapped the damages in vineyards after a hailstorm using spatial analysis methods on WebGIS. Aicardi et al. (2015) documented the landscape heritage exposed to a disaster by using multi-platform data (e.g. terrestrial and airborne LiDAR, close range and aerial photogrammetry, etc.) and shared with the local authorities via a WebGIS portal.

When the 3D geovisualization platforms for disaster management purposes in the literature are considered; the EqMap3D system developed by $\mathrm{Li}$ et al. (2015) is a 3D earthquake information sharing platform in real-time based on NASA WorldWind. Chen et al. (2016) developed a 2D/3D WebGIS platform for landslide hazard management. The platform allows concurrent access of multiple stakeholders including local authorities to the web environment with advanced analytic functionality. Jacquinod and Bonaccorsi (2019) evaluated the role of 3D geovisualization for flood mitigation planning and emphasized that further studies are needed to understand the characteristics of $3 \mathrm{D}$ visualization and to solve the issues related to the uses with citizens.

Citizen science (CitSci) and participatory GIS applications have been proposed for natural disaster management studies, in which volunteers contribute to data collection, processing, interpretation, and analysis; and to support the dissemination of results. Pirotti et al. (2011) presented a collaborative WebGIS framework for automatic analysis and updating of spatial statistics regarding road risk analysis and monitoring. Kocaman and Gokceoglu (2018) presented potential of CitSci and volunteered geographic information (VGI) in natural hazard assessment. In this context, Kocaman and Gokceoglu (2019) developed a mobile app called LaMa for landslide data collection with a simple and user-friendly interface. Can et al. (2019) developed a convolutional neural network (CNN) algorithm for assessing the quality of the collected landslide photos; and later integrated the whole process as an artificial intelligence-supported WebGIS platform (Can et al., 2020). Yalcin et al. (2020) implemented a mobile and web-based GIS platform to demonstrate the usability of data provided by citizen scientists for rapid production of earthquake iso-intensity maps.

\section{STUDY AREA AND DATASETS}

\subsection{Study Area Characteristics and the Earthquake Event}

The study area is located inside Elazig and Malatya Provinces, Turkey. The topography in the region is very young and steep due to high seismicity and active tectonism (Karakas et al., 2021). According to the Disaster and Emergency Management Authority (AFAD) of Turkey, the earthquake event with $\mathrm{Mw}$ 6.8 occurred on January 24, 2020, at 20:55 local time on HazarSincik segment of East Anatolian Fault Zone (EAFZ) (AFAD, 
2020). Its duration and depth were 20.4 seconds and $8.06 \mathrm{~km}$. The closest settlement to the earthquake epicenter is the Çevrimtas village of Sivrice town in Elazig Province with a distance of ca. 800 meters. The location of the study area is depicted in Figure 1. The size of the area is ca. $3000 \mathrm{~km}^{2}$.
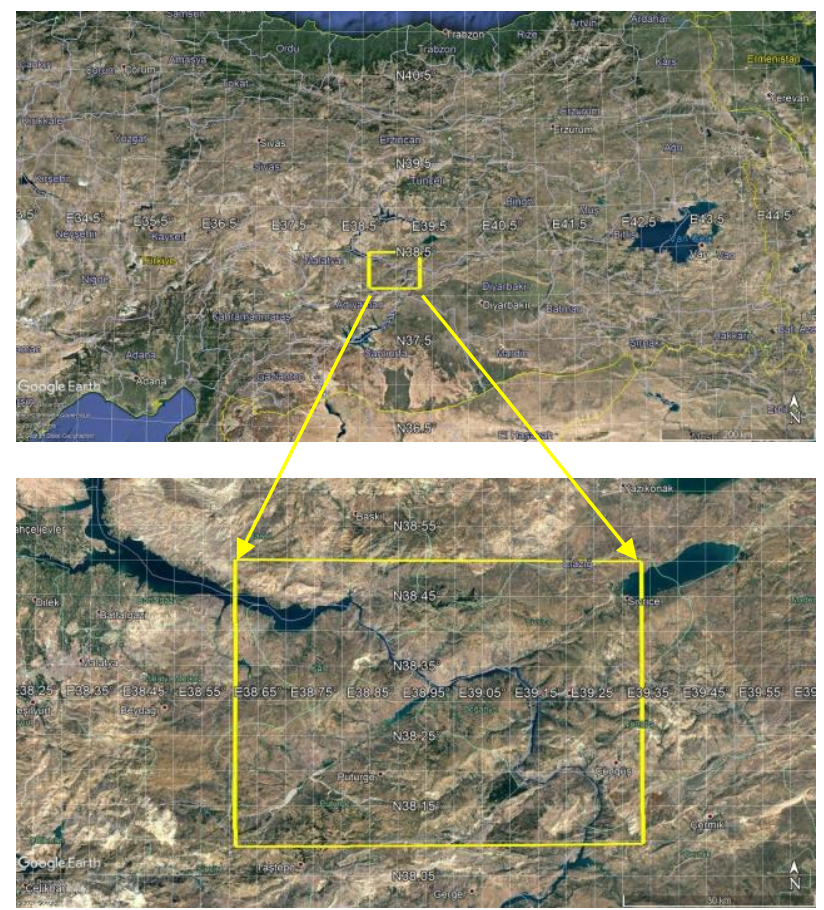

Figure 1. The location and the boundary of the study area.

\subsection{Study Datasets}

Geospatial datasets from various platforms with the closest acquisition dates to the event (before and after) were preferred here. The general characteristics of the data used on EQ4D are presented in Table 1. Three sets of aerial photogrammetric mission data, two in years 2017 and 2018, and the last one two days after the event were acquired by the GDM. The digital surface models (DSMs) and orthophotos were produced from these stereo datasets (Gokceoglu et al., 2020). The horizontal and vertical point positioning accuracies of the datasets were in the order of ca. 5-15 cm depending on the resolution. Several spatial analysis methods were carried out with the aerial DSMs and orthophotos (Gokceoglu et al., 2020). 2D displacements obtained from the matching of orthophotos of before and after the earthquake were visualized in order to analyze the changes in planimetry. The residuals obtained from the DSM comparison were derived for visualizing the differences in vertical direction (Karakas et al., 2021). The photogrammetric datasets, their processing and the volumetric change detection analyses were described in more detail in Karakas et al. (2021).

Synthetic aperture radar (SAR) and optical datasets acquired by the Sentinel-1 and Sentinel-2 satellites of European Space Agency (ESA, 2021) and provided freely via the Copernicus Open Access Center (Copernicus, 2021) were utilized here since they have a regular data acquisition scheme globally. Sentinel-1A/1B interferometric SAR (InSAR) data acquired closely before and after the event were utilized for the surface deformation analysis and the determination of displacement caused by the tectonic activity (Gokceoglu et al., 2020). The InSAR technique analyzes the phase differences of data acquired at two different times of the same region; and allows the measurement of 3D changes with respect to the line of sight (LOS). Sentinel-2 mission image mosaics acquired before $(2019 / 09 / 05)$ and after the earthquake (2020/07/21) were also employed in EQ4D.

\begin{tabular}{|c|l|c|c|c|}
\hline $\begin{array}{c}\text { Dataset } \\
\text { ID }\end{array}$ & \multicolumn{1}{|c|}{ Description } & $\begin{array}{c}\text { Origin / } \\
\text { producer }\end{array}$ & $\begin{array}{c}\text { Spatial } \\
\text { Resolution }\end{array}$ & $\begin{array}{c}\text { Production/ } \\
\text { Acquisition } \\
\text { Date }\end{array}$ \\
\hline 1 & $\begin{array}{l}\text { Pre-event aerial } \\
\text { photogrammetric } \\
\text { datasets }\end{array}$ & GDM & $30 \mathrm{~cm}$ & $\begin{array}{c}\text { Years 2017 } \\
\text { and 2018 }\end{array}$ \\
\hline 2 & $\begin{array}{l}\text { Post-event aerial } \\
\text { photogrammetric } \\
\text { datasets }\end{array}$ & GDM & $20 \mathrm{~cm}$ & 26 Jan 2020 \\
\hline 3 & Sentinel-1 InSAR & ESA & $10 \mathrm{~m}$ & $\begin{array}{l}16.01 .2020 / \\
22.01 .2020 / \\
28.01 .2020 / \\
03.02 .2020\end{array}$ \\
\hline 4 & $\begin{array}{l}\text { Sentinel-2 satelite } \\
\text { optical images }\end{array}$ & ESA & 10 m - 60 & $\begin{array}{c}2019 / 09 / 05 \\
2020 / 07 / 21\end{array}$ \\
\hline 5 & $\begin{array}{l}\text { TopoVT national } \\
\text { vector map } \\
\text { database }\end{array}$ & GDM & N.A.* & unknown \\
\hline 6 & OSM Vector & OSM & N.A.* & unknown \\
\hline 7 & $\begin{array}{l}\text { Earthquake events } \\
\text { (WFS) }\end{array}$ & USGS & N.A.* & Real time \\
\hline 8 & $\begin{array}{l}\text { Earthquake events } \\
\text { (static) }\end{array}$ & AFAD & N.A.* & $\begin{array}{c}2020 / 01 / 20- \\
2021 / 04 / 15\end{array}$ \\
\hline 9 & Basemaps & Various & N.A.* & unknown \\
\hline
\end{tabular}

Table 1. The input datasets used in the study. *Not Applicable

The TopoVT dataset is composed of numerous spatial layers contained in the national vector map database and provided by the GDM for the purposes of the study. The open source OpenStreetMap (OSM, 2021) vector data was also downloaded for a visual comparison with the TopoVT dataset. The Earthquake Catalog of the U.S. Geological Survey (USGS, 2021) was employed as web feature service (WFS) in the system for disseminating recent earthquake events on the EQ4D. In addition, earthquake information obtained from AFAD was also included in the platform. Furthermore, several basemaps such as OSM building data and the other globally available base maps (e.g. Bing Maps, ArcGIS World Street Map, US USGS shaded relief map) were presented in the EQ4D in the form of web map service (WMS).

\section{METHODS}

The overall workflow of the study is presented in Figure 2. Based on the data availability and the functional requirements analysis based on the interviews with geoscientists, the system functionalities, which have higher priority and could be developed within the project timeframe, were determined as;

i) $3 \mathrm{D}$ visualization of multi-source datasets

ii) representation of dynamic phenomena via web services

iii) a web interface with mensuration tools

iv) vector drawing tools

v) change detection

The system was designed and implemented after exploring the available free and open source technologies. Further details are provided in the next sections. 


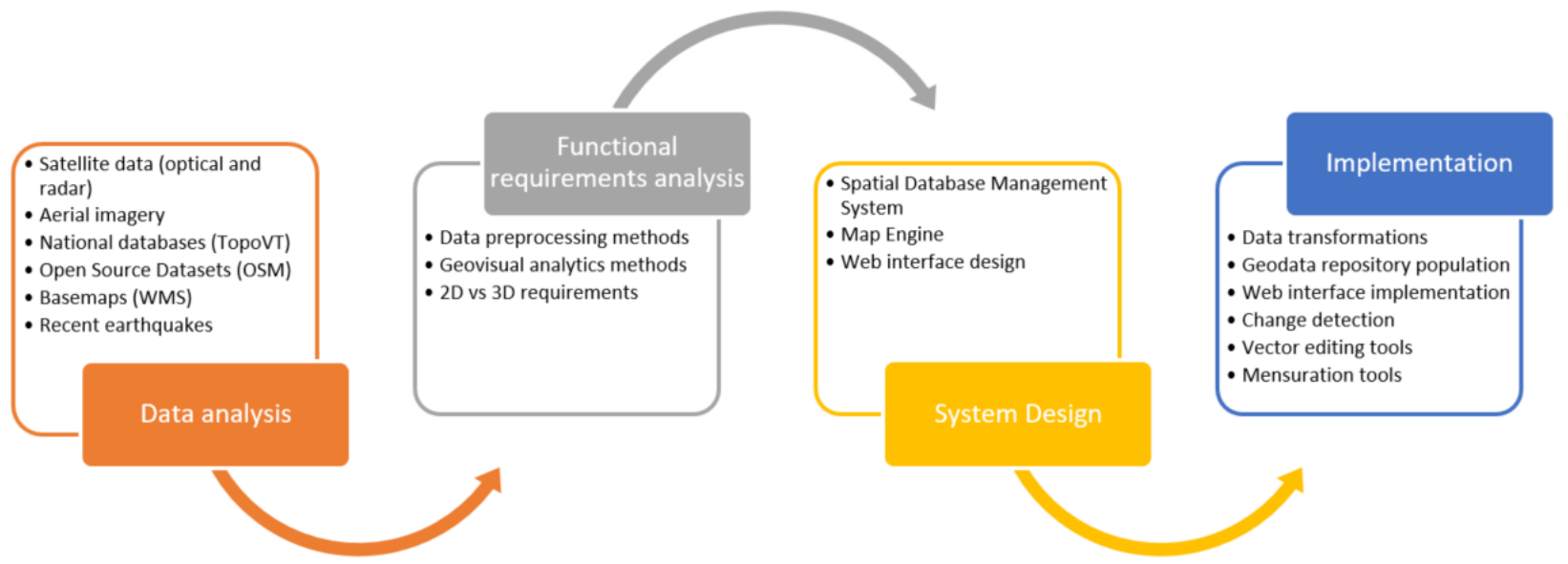

Figure 2. The overall workflow of the study.

\subsection{The System Architecture}

A web-based virtual globe platform was designed with a classical web architecture that consists of a server and a client (Figure 3). The server-side software is operated on the server, and client-side software runs on the user's web browser. The client-side web development models the user interactions with the system and displays the data. The CesiumJS (v1.74), which is an open source JavaScript library for virtual globe (Cesium, 2021); and the open source Potree (v1.7.1) library (Potree, 2021) were utilized complementarily as $3 \mathrm{D}$ visualization environments due to various advantages and disadvantages as described by Buyukdemircioglu and Kocaman (2018). Furthermore, a spatial database management system (SDBMS) was needed for storing the manual delineations, which were added to the EQ4D as drawing functionality such as point, line, polygon (circles, rectangles) drawing, etc. Also, Potree allows users to view billions of points obtained from various sensors, such as LIDAR (Light Detection and Ranging) sensors or optical images, in real time on standard web browsers. This library was utilized for high-performance visualization of point clouds.

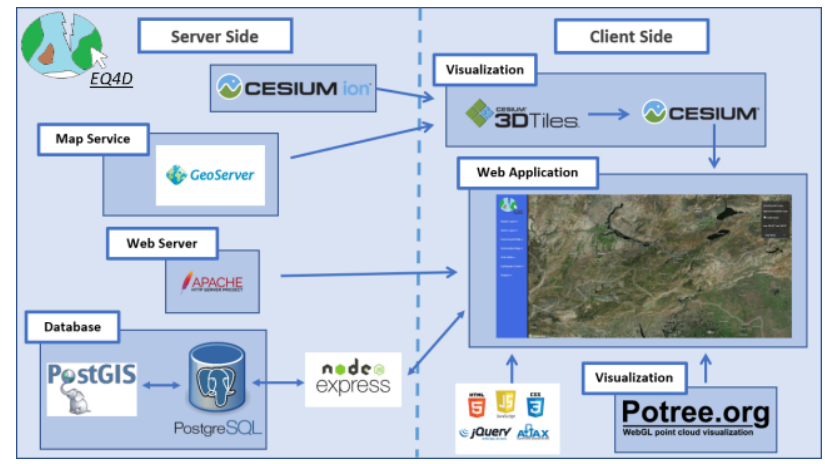

Figure 3. EQ4D system schema with client/server architecture and software components.

The server-side operations were performed behind the scenes and have different purposes such as the data and software management, processing, etc. Apache HTTP server v2.4 (Apache, 2021) and Geoserver v2.15.1 (Geoserver, 2021) were utilized, while server-side programming language Node.js (v15.2.0) and Express (v4.17.1) module were selected. Also, Postgresql v12.5 with PostGIS v3.1.0 (PostGIS, 2021) extension is used spatial database. Cesium ION (Cesium, 2021) is an online platform for tiling, optimizing, and hosting 3D data. Built on the modern cloud architecture, the application can efficiently stream large datasets into web applications like CesiumJS that can be shared with others across any device.

\subsection{Population of the Geodata Repository}

The input datasets were provided in various formats, such as vector data, multispectral images, raster grid, irregular point clouds, WFS and WMS (Table 2). A distributed data storage structure was preferred here due to the different capabilities and the requirements of the selected technologies. The orthophotos, the DSMs and the outputs of 2D/3D change detection methods were presented on the EQ4D via Geoserver.

\begin{tabular}{|l|c|c|c|}
\hline Data & Format & Size & Location \\
\hline TopoVT & geojson & $193 \mathrm{MB}$ & CesiumION \\
\hline OSM & geojson & $34.4 \mathrm{MB}$ & CesiumION \\
\hline $\begin{array}{l}\text { Point Cloud for } \\
\text { Cesium }\end{array}$ & las & $784 \mathrm{MB}$ & CesiumION \\
\hline $\begin{array}{l}\text { Point Cloud for } \\
\text { Potree }\end{array}$ & js & $459 \mathrm{MB}$ & $\begin{array}{c}\text { Local } \\
\text { Directory }\end{array}$ \\
\hline $\begin{array}{l}\text { INSAR - } \\
\text { Displacement } \\
\text { Horizontal }\end{array}$ & $\mathrm{kmz}$ & $9.08 \mathrm{MB}$ & CesiumION \\
\hline $\begin{array}{l}\text { INSAR - } \\
\text { Displacement } \\
\text { Vertical }\end{array}$ & $\mathrm{kmz}$ & $11.37 \mathrm{MB}$ & CesiumION \\
\hline AFAD & $\mathrm{kml}$ & $103.3 \mathrm{~KB}$ & CesiumION \\
\hline $\begin{array}{l}\text { Ortophoto - } \\
\text { Displacement } \\
\text { Horizontal }\end{array}$ & geojson & $1.04 \mathrm{MB}$ & Geoserver \\
\hline $\begin{array}{l}\text { Ortophoto - } \\
\text { Displacement } \\
\text { Vertical }\end{array}$ & tif & $147 \mathrm{MB}$ & Geoserver \\
\hline Ortophotos & tif & $264 \mathrm{MB}$ & Geoserver \\
\hline $\begin{array}{l}\text { Sentinel-2 satelite } \\
\text { optical images }\end{array}$ & tif & $1.34 \mathrm{~GB}$ & Geoserver \\
\hline DSMs & tif & $360 \mathrm{MB}$ & Geoserver \\
\hline Change Detection & tif & $1.08 \mathrm{~GB}$ & Geoserver \\
\hline
\end{tabular}

Table 2. The formats and storage locations of the spatial datasets. 


\subsection{Implementation of Geospatial Analysis Methods}

The vector drawing tools are connected with the PostGIS and each feature is recorded with attributes in the database. Figure 4 depicts the SQL statement for the definition of the table, which stores the output of the drawing tools. In the statement, the "id" is the primary key with integer data type and progresses in increments. The "datatype" is stored as text and cannot be null in the database. The "name" and "information" fields are custom attributes to be filled out by users as text. The "Geom" field is records the geometries of the features as jsonb data type in the database and cannot be null. The "createdAt" field stores the date, day and time when the feature is added to the database automatically.

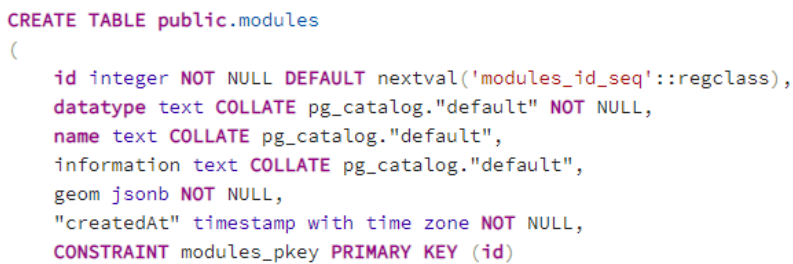

Figure 4. SQL CREATE TABLE data definition statements for defining the drawing tools schema.

Although the spatial analysis procedures or visual analytics functionality which can be performed on the platform are numerous, only the change detection was implemented at the current stage. The change detection results both in $2 \mathrm{D}$ and $3 \mathrm{D}$ can guide the users by pointing out the particular areas of interest for rapid mapping of disaster affected areas and infrastructure. Besides, drawing tools have been developed for geoscience experts to create a point, line, polygon, rectangle, and a circle at a specified point on the $3 \mathrm{D}$ virtual sphere. While drawing a circle, the Euclidean Distance between two points selected from the area is the radius. A circle is drawn with the radius determined from the first point selected. Although further analysis and feature types, such as land use and land cover in the region, frequently used topographic derivatives, i.e. slope and aspect, can also be added to the system; they are planned as future work.

Change detection methods allow to identify the changes in a given time frame by using multi-temporal datasets. This functionality was given priority in the study to facilitate the damage mapping, e.g. collapsed buildings, and observing the other surface changes such as landslide hazards caused by the earthquake. Therefore, orthophotos obtained from pre- and post-earthquake images were used here for a simple change detection analysis based on pixel intensity values. Since the aerial images were taken at different seasons, i.e. end of summer and mid-winter, they have different amount of exposures to daylight and atmospheric effects, which eventually lead to radiometric biases between them. Thus, areas without any changes also exhibit radiometric differences. Therefore, a number of radiometric analysis methods and corrections were applied on the orthophotos. For example, over water surfaces, the pixel values were expected to be similar in both orthophotos and also close to zero. The intensity values of water pixels were employed to shift the histograms of both images. Another method, which was used here, was to equalize the histogram mean values 127 ( 8 bit images) again by shifting. The mean brightness value obtained from all three bands of the 2018 image was 144.48; and the histogram was shifted by a constant value of 17.48 to have an average of 127 . The amount of data lost by the shift was $0.036 \%$. With the applied method, the data lost by the shifting was $0.52 \%$, which was considered as acceptable, in the orthophotos of 2020. The 2018 and 2020 images were simply subtracted for all bands to obtain the areas with changes.

\section{RESULTS AND DISCUSSIONS}

The main interface components of the EQ4D include layer presentation, map area, and toolbar menus. The layer presentation menu (1) available on the platform and depicted in Figure 5 includes in the order of top-to-down: (1.1) basemaps and raster layers; (1.2) vector layers; (1.3) point clouds; (1.4) deformation data layers; (1.5) grid DSMs visualization; (1.6) earthquake events; and (1.7) outputs of spatial analyses. The toolbar menu (2) includes the functionality of: (2.1) visualization of features previously drawn and added to the system; (2.2) display of the cursor position on the globe; (2.3) drawing tools and viewing mode. Furthers snapshots of the EQ4D menus and the data available on the developed platforms are presented in Figures 5-11.

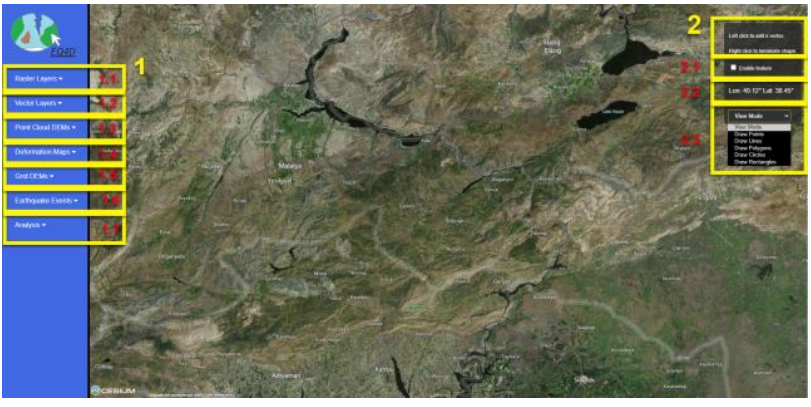

Figure 5. The main interface layout and the menus of EQ4D.

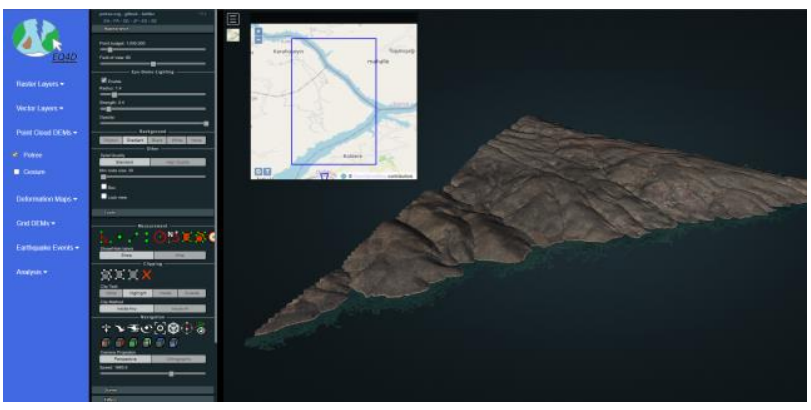

Figure 6. Visualization of point cloud DSM with Potree.

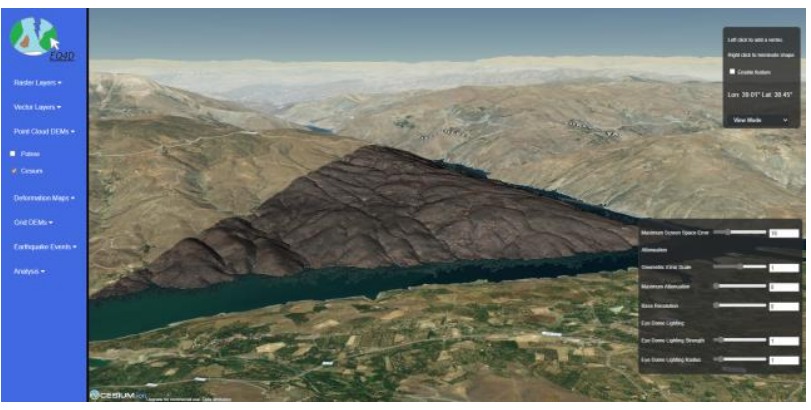

Figure 7. Visualization of point cloud DSM with Cesium. 


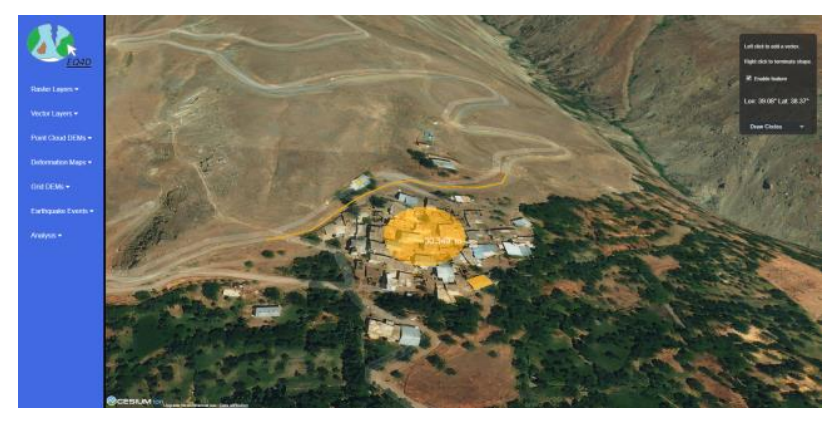

Figure 8. Visualization of delineated features by the users.

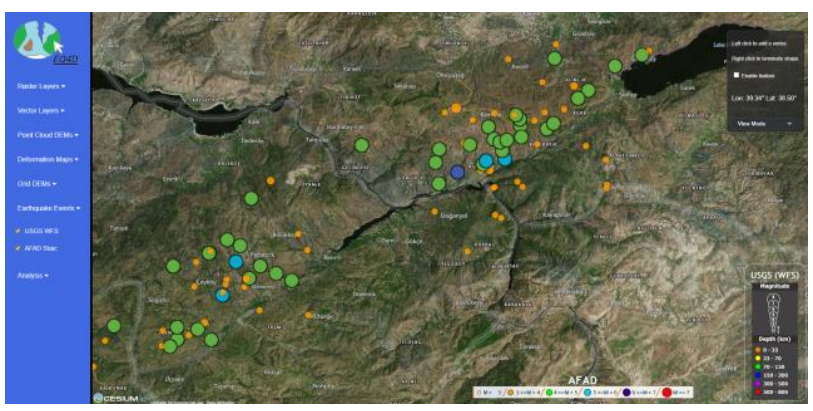

Figure 9. Visualization of recent earthquake events.

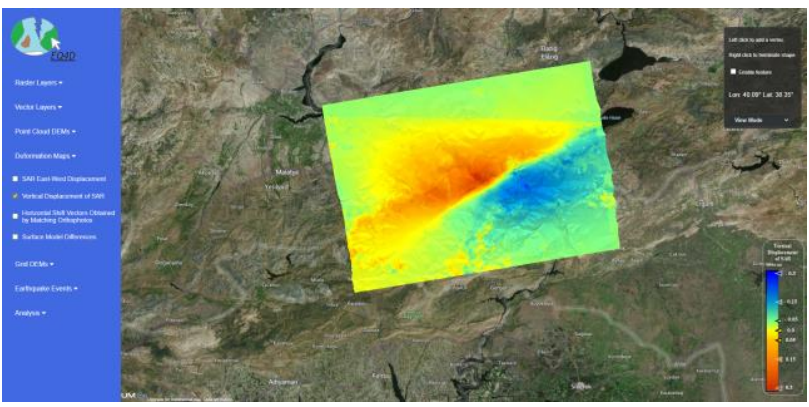

Figure 10. Visualization of vertical displacement data obtained with SAR images (data courtesy: Gokceoglu et al., 2020).

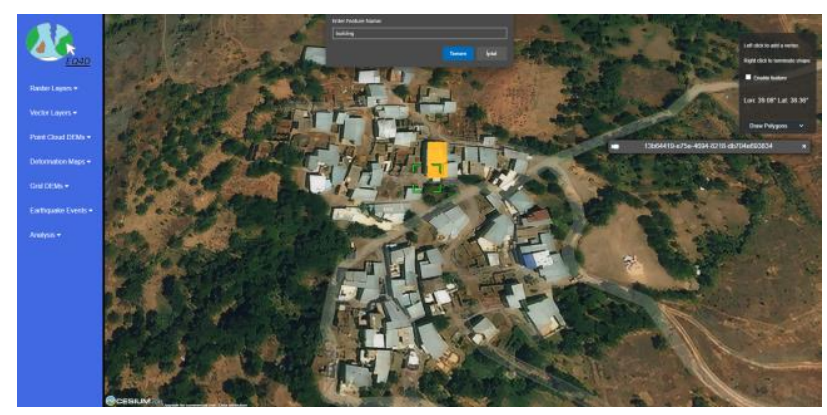

Figure 11. Polygon drawing tool.

The change detection results obtained from the 2018 and 2020 orthophotos are presented in Figures 12 and 13. The analysis results were interpreted by classifying the differences as significant or minor decrease, no change (the difference value is equal to zero), and significant or minor increase. The minimum and maximum change values were -246.48and 180.63. The thresholds between the minor and significant change classes were obtained from halving these values.

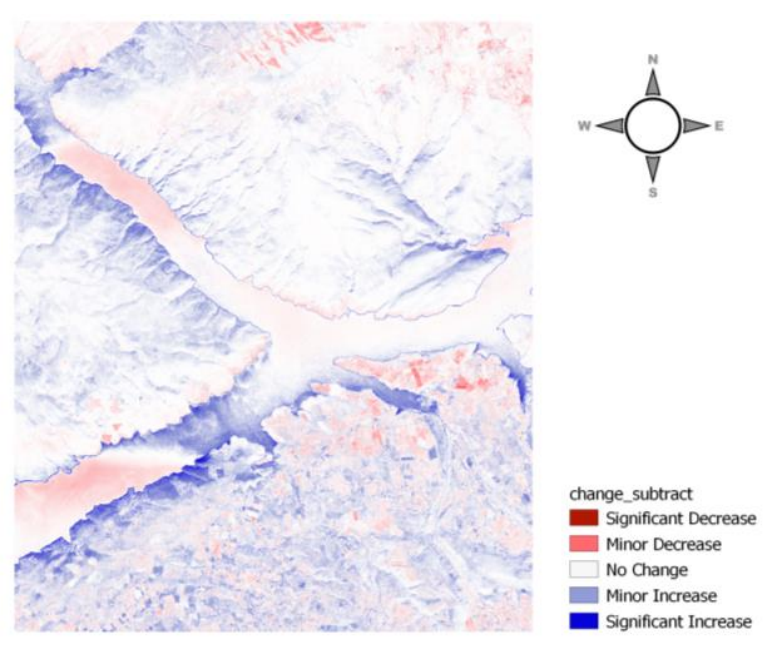

Figure 12. The image change detection results.

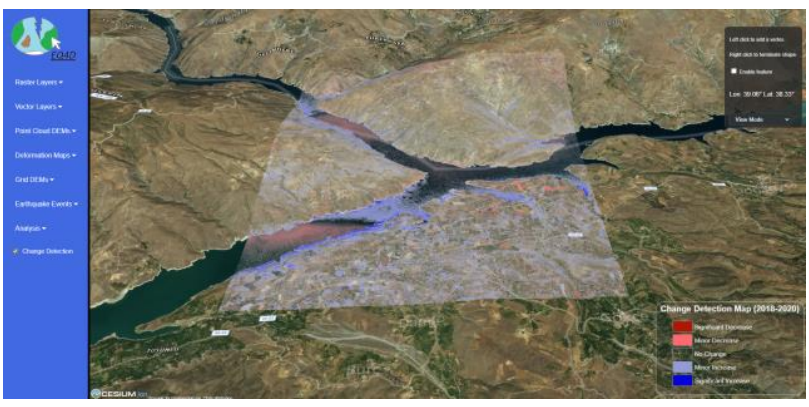

Figure 13. Visualization of image change detection results on the EQ4D platform.

\section{CONCLUSIONS AND FUTURE WORK}

One of the goals of this study was to present the multi-platform and multi-temporal geodata obtained before and after an earthuquake disaster in the study area in a user-friendly 4D environment for geoscientists and citizen scientists. In addition, the necessary geo-analytics tools for the interpretation and analysis of post-earthquake assessment of the buildings, infrastructure elements, damaged areas, landslides, etc. have been developed and presented here. The EQ4D has the potential to support the improved communication of various stakeholders and decision-makers for the disaster management purposes.

As stated by Scheider et al. (2020), future work on geoanalytical processes need to describe the analytic potential of methods and datasets. Thus, the platform can be developed further by benefiting from user experiences and requirements in different hazard assessment and disaster management studies.

\section{ACKNOWLEDGEMENTS}

This research is part of the M.Sc. thesis of the first author. The authors sincerely thank to the GDM, Turkey, Beste Tavus, Mehmet Buyukdemircioglu, Recep Can, Gizem Karakas and Candan Gokceoglu for providing the Elazig datasets and their continuous support.

\section{REFERENCES}

AFAD (Disaster and Emergency Management Presidency of Turkey) (2020). Report on the 24 January 2020 Sivrice (Elazig) 
Earthquake.

$47 \mathrm{p}$, https://deprem.afad.gov.tr/downloadDocument?id=1831 (3 Apr 2021).

Aicardi, I., Boccardo, P., Chiabrando, F., Facello, A., Gnavi, L., Lingua, A., Pasquale, F., Maschio, P., Spanò, A., 2015. A didactic project for landscape heritage mapping in post-disaster management. Appl Geomat 7, 49-60. https://doi.org/10.1007/s12518-014-0144-x

Apache, 2021. The Apache HTTP Server Project https://httpd.apache.org/ (17 Apr 2021).

Aye, Z. C., Sprague, T., Cortes, V. J., Prenger-Berninghoff, K., Jaboyedoff, M., \& Derron, M. H. (2016). A collaborative (webGIS) framework based on empirical data collected from three case studies in Europe for risk management of hydrometeorological hazards. International Journal of Disaster Risk Reduction, 15, 10-23. Doi: 10.1016/j.ijdrr.2015.12.001

Boulos, M.N.K., Koh, K., 2021. Smart city lifestyle sensing, big data, geo-analytics and intelligence for smarter public health decision-making in overweight, obesity and type 2 diabetes prevention: the research we should be doing. Int J Health Geogr 20, 12 (2021). https://doi.org/10.1186/s12942-021-00266-0

Buyukdemircioglu, M., Kocaman, S., 2018. A 3D Campus Application Based On City Models And WebGL. ISPRS - Int. Arch. Photogramm. Remote Sens. Spat. Inf. Sci. XLII-5, 161165. https://doi.org/10.5194/isprs-archives-XLII-5-161-2018

Buyukdemircioglu, M., Kocaman, S., 2020. Reconstruction and Efficient Visualization of Heterogeneous 3D City Models. Remote Sens. 12, 2128. https://doi.org/10.3390/rs12132128

Can, R., Kocaman, S., Gokceoglu, C., 2019. A convolutional neural network architecture for auto-detection of landslide photographs to assess citizen science and volunteered geographic information data quality. ISPRS International Journal of Geo-Information, 8(7), 300 . https://doi.org/10.3390/ijgi8070300

Can, R., Kocaman, S., Gokceoglu, C., 2020. Development of a CitSci and Artificial Intelligence Supported GIS Platform for Landslide Data Collection. ISPRS - Int. Arch. Photogramm. Remote Sens. Spat. Inf. Sci. XLIII-B5-2020, 43-50. https://doi.org/10.5194/isprs-archives-XLIII-B5-2020-43-2020

Cesium, 2021. CESIUM https://cesium.com/platform/cesium-ion/ (17 April 2021).

Chen, W., He, B., Zhang, L., Nover, D., 2016. Developing an integrated 2D and 3D WebGIS-based platform for effective landslide hazard management. International Journal of Disaster Risk Reduction, 20, 26-38. Doi: 10.1016/j.ijdrr.2016.10.003

Cook, K.A., Thomas, J.J., 2005. Illuminating the path: the research and development agenda for visual analytics. IEEE Computer Society.

Copernicus, 2021. Copernicus Open Access Hub. https://scihub.copernicus.eu/dhus/\#/home (17 April 2021).

ESA, 2021. European Space Agency Sentinel Overview. https://sentinel.esa.int/web/sentinel/missions (4 Apr 2021).
Fernando, N., Waidyasekara, S., Dias, D., 2006. A System based on Web-GIS for Post-Disaster Recovery Management, in: IEE 2006 International Conference on Information and Automation. Presented at the 2006 International Conference on Information and Automation, pp. 75-80. https://doi.org/10.1109/ICINFA.2006.374155

Geoserver, 2021. http://geoserver.org/ (17 April 2021).

Gokceoglu, C., Yurur, T., Kocaman, S., Nefeslioglu, H., Durmaz, M., Tavus, B., Karakaş, G., Büyükdemircioğlu, M., Atasoy, K., Yörük, I., Can, R., Yalçın, I., 2020. Radar İnterferometrisi Ve Stereo Hava Fotogrametrisi İle Elaziğ Sivrice Depreminin (24 Ocak 2020, M W =6.8) İncelenmesi. https://doi.org/10.13140/RG.2.2.19673.88167

Heinzlef, C., Becue, V., Serre, D., 2020. A spatial decision support system for enhancing resilience to floods: bridging resilience modelling and geovisualization techniques. Nat. Hazards Earth Syst. Sci. 20, 1049-1068. https://doi.org/10.5194/nhess-20-1049-2020

He, Y., Zhang, D., Fang, Y., 2017. Development of a mobile post-disaster management system using free and open source technologies. International journal of disaster risk reduction, 25, 101-110. Doi: 10.1016/j.ijdrr.2017.08.007

Ho, Q., Jern, M., 2008. Interacting with 4D oceanographic volume data using GeoAnalytics tools. National Center for Visual Analytics NCVA, Linköping University, Sweden.

Jacquinod, F, Bonaccorsi, J., 2019. Studying Social Uses of 3D Geovisualizations: Lessons Learned from Action-Research Projects in the Field of Flood Mitigation Planning. ISPRS International Journal of Geo-Information, 8(2), 84 https://doi.org/10.3390/ijgi8020084

Jern, M., Franzen, J., 2006. "GeoAnalytics" - Exploring spatiotemporal and multivariate data. Tenth International Conference on Information Visualisation (IV'06), London, UK, 2006, pp. 25-31, doi: 10.1109/IV.2006.1.

Karakas, G., Nefeslioglu, H. A., Kocaman, S., Buyukdemircioglu, M., Yurur, T., Gokceoglu, C., 2021. Derivation of earthquake-induced landslide distribution using aerial photogrammetry: the 24 January 2020 Elazig (Turkey) Earthquake. Landslides, 1-17. https://doi.org/10.1007/s10346021-01660-2

Keehner, M., Montello, D., Fabrikant, S., Riggs, E.M., Dalton, R.C., 2011. Everyday Cognitive Science: Using the methods of cognitive science to explore spatial thinking in related disciplines. In Proceedings of the Annual Meeting of the Cognitive Science Society (Vol. 33, No. 33). https://escholarship.org/uc/item/7866k3rf (4 Apr 2021)

Kilsedar, C.E., Brovelli, M.A., 2020. Multidimensional Visualization and Processing of Big Open Urban Geospatial Data on the Web. ISPRS Int. J. Geo-Inf. 9, 434. https://doi.org/10.3390/ijgi9070434

Kocaman, S., Gokceoglu, C., 2018. On the Use of CitSci and VGI in Natural Hazard Assessment. International Archives of the Photogrammetry, Remote Sensing \& Spatial Information Sciences, 42(5), 69-73. https://doi.org/10.5194/isprs-archivesXLII-5-69-2018 
Kocaman, S., Gokceoglu, C., 2019. A CitSci app for landslide data collection. Landslides 16, 611-615. https://doi.org/10.1007/s10346-018-1101-2

Kocaman, S., Ozdemir, N., 2020. Improvement of Disability Rights via Geographic Information Science. Sustainability, 12(14), 5807. https://doi.org/10.3390/su12145807

Lagmay, A.M.F.A., Racoma, B. A., Aracan, K.A., AlconisAyco, J., Saddi, I.L., 2017. Disseminating near-real-time hazards information and flood maps in the Philippines through Web-GIS. Journal of Environmental Sciences, 59, 13-23. https://doi.org/10.1016/j.jes.2017.03.014

Lan, H., Derek Martin, C., Lim, C.H., 2007. RockFall analyst: A GIS extension for three-dimensional and spatially distributed rockfall hazard modeling. Comput. Geosci. 33, 262-279. https://doi.org/10.1016/j.cageo.2006.05.013

Li, B., Wu, J., Pan, M., Huang, J., 2015. Application of 3D WebGIS and real-time technique in earthquake information publishing and visualization. Earthq Sci 28, 223-231. https://doi.org/10.1007/s11589-015-0124-1

Li, W., Wang, S., 2017. PolarGlobe: A web-wide virtual globe system for visualizing multidimensional, time-varying, big climate data. Int. J. Geogr. Inf. Sci. 31, 1562-1582. https://doi.org/10.1080/13658816.2017.1306863

Lovett, A., Appleton, K., Warren-Kretzschmar, B., Von Haaren, C., 2015. Using 3D visualization methods in landscape planning: An evaluation of options and practical issues. Landsc. Urban Plan., Special Issue: Critical Approaches to Landscape Visualization 142, 85-94. https://doi.org/10.1016/j.landurbplan.2015.02.021

NASA WorldWind, 2014. http://worldwind.arc.nasa.gov. (4 Apr 2021)

OSM, 2021. OpenStreetMap. www.openstreetmap.org (16 April 2021)

Pfeffer, K., Georgiadou, Y., 2019. Global ambitions, local contexts: Alternative ways of knowing the world. ISPRS Int. J. Geo-Inf., 8, 516. https://doi.org/10.3390/ijgi8110516

Pirasteh, S., 2018. Landslide Geoanalytics Using LiDARderived Digital Elevation Models. Ph.D. thesis submitted to the Dept. of Geography, University of Waterloo, Ontario, Canada.

Pirotti, F., Guarnieri, A., Vettore, A., 2011. Collaborative WebGIS Design: A Case Study for Road Risk Analysis and Monitoring. Transactions in GIS 15, 213-226. https://doi.org/10.1111/j.1467-9671.2011.01248.x

PostGIS, 2021. https://postgis.net/ (17 April 2021)

Potree, 2021. https://github.com/potree/potree/ (16 April 2021)

Scheider, S., Nyamsuren, E., Kruiger, H., Xu, H., 2020. Geoanalytical question-answering with GIS. International Journal of Digital Earth, 1-14. Doi: 10.1080/17538947.2020.1738568

Schumann, H., Tominski, C., 2011. Analytical, visual and interactive concepts for geo-visual analytics. Journal of Visual
Languages \& Computing, 22(4), 257-267. https://doi.org/10.1016/j.jvlc.2011.03.002

Scott, G., Rajabifard, 2017. A. Sustainable development and geospatial information: A strategic framework for integrating a global policy agenda into national geospatial capabilities. Geo$\begin{array}{llll}\text { Spat. } & \text { Inf. } & \text { Sci., } & \text { 59-76. }\end{array}$ https://doi.org/10.1080/10095020.2017.1325594

Stoter, J., Kluijver, H. de, Kurakula, V., 2008. 3D noise mapping in urban areas. Int. J. Geogr. Inf. Sci. 22, 907-924. https://doi.org/10.1080/13658810701739039

Sylka, M., Bandrova, T., Kuka, Y., Ajvazi, B., 2018. Use Of The Web Gis For The Post - Disaster Management: A Case Of Mapping The Damaged Vineyards Areas Caused By Hailstorm. Presented at the 7th International Conference on Cartography and GIS, Sozopol, Bulgaria.

UN, 2015. Sendai Framework for Disaster Risk Reduction 2015 -2030 .

https://www.preventionweb.net/files/43291_sendaiframeworkfo rdrren.pdf (3 March 2021)

UN SDGs, 2020. Global indicator framework for the Sustainable Development Goals and targets of the 2030 Agenda for Sustainable Development. Technical report. E/CN.3/2020/2 https://unstats.un.org/sdgs/indicators/Global\%20Indicator\%20F ramework\%20after\%202020\%20review_Eng.pdf (3 April 2021).

USGS, 2021. U.S. Geological Survey. https://www.usgs.gov/ (16 April 2021).

Vučić, N., Mađer, M., Pivac, D., Roić, M., Križanović, J., 2020. Determination of a Hazard Compensations Based on Land Administration Data. ISPRS International Journal of GeoInformation 9, 71. https://doi.org/10.3390/ijgi9020071

Yalcin, I., Kocaman, S., Gokceoglu, C., 2020. A CitSci Approach for Rapid Earthquake Intensity Mapping: A Case Study from Istanbul (Turkey). ISPRS International Journal of Geo-Information 9, 266. https://doi.org/10.3390/ijgi9040266

Zhang, X., Zhang, M., Jiang, L., Yue, P., 2020. An interactive 4D spatio-temporal visualization system for

hydrometeorological data in natural disasters. Int J of Digital Earth 13, 1258-1278. Doi: 10.1080/17538947.2019.1701110

Zhilin, L.I., Gong, X., Chen, J., Mills, J., Songnian, L.I., Zhu, X.U., Peng, T.I. and Hao, W.U., 2020. Functional requirements of systems for visualization of sustainable development goal (SDG) indicators. Journal of Geovisualization and Spatial Analysis, 4(1), pp.1-10. https://doi.org/10.1007/s41651-0190046-x 